\title{
Complementary Assets, Start-Ups and Incentives to Innovate
}
L. Colombo
H. Dawid 


\title{
Complementary Assets, Start-Ups and Incentives to Innovate*
}

\author{
Luca Colombo ${ }^{\dagger} \quad$ Herbert Dawid ${ }^{\ddagger}$
}

March 2013

\begin{abstract}
In this paper we examine to what extent market conditions facilitating start-up formation affect technical change and firms' profits. We consider a model in which $\mathrm{R} \& \mathrm{D}$ efforts of an incumbent firm generate partly tacit technological know-how embodied in a key R\&D employee, who might use it to form a start-up. The availability of complementary assets influences whether new firms are created and determine expected profits for start-up-founders. A large availability of complementary assets has the direct effect that the generation of start-ups is fostered. However, as a strategic effect, the incentives of incumbent firms to invest in R\&D might be reduced because of the increased danger of knowledge loss occurring through start-up formation. We fully characterize the effects of an increase in the availability of complementary assets, showing under which conditions the effects on innovative activities and industry profits are negative.
\end{abstract}

JEL classification: L20, M13, O32

Keywords: Tacit Knowledge, Complementary Assets, Technological Change, R\&D Effort, Start-Up Creation

\section{Introduction}

The main goal of this paper is to investigate the effects of the availability of complementary assets needed for start-up formation on the amount of R\&D investments by an incumbent firm, and on the creation of start-ups by former employees.

The mechanisms by which innovative technologies come about and make their way into the economy have been the object of a large literature, arguing that the flows of knowledge embodied in employees often facilitate technological diffusion. A particular instance of key employees' mobility is the creation of start-up firms. The available

\footnotetext{
*Financial support from the German Science Foundation (DFG) under grant GRK1134/2 (International Research and Training Group 'Economic Behavior and Interaction Models' - EBIM) and from the Italian Ministry of Research under grant PRIN - 'Non Linear Models in Economics and Finance' is gratefully acknowledged.

${ }^{\dagger}$ Università Cattolica del Sacro Cuore, Largo Gemelli 1, I-20123 Milano, Italy. E-mail: lucava.colombo@unicatt.it, Phone: +390272342637, Fax: +390272342781.

${ }^{\ddagger}$ Bielefeld University, P.O. Box 100131, D-33501 Bielefeld, Germany. E-mail: hdawid@wiwi.unibielefeld.de.
} 
empirical evidence shows indeed that the evolution of many industries is to a large extent driven by the entry of start-ups created by former employees of incumbents (see, e.g., Dahl, Ostergaard, and Dalum (2010), Klepper and Sleeper (2005), Klepper (2010)). Start-up generation is seen as an important mechanism for the determination of market structure and the propagation of technical change (see, e.g., Acs and Plummer (2005)). However, as pointed out by Klepper (2001, p. 639) start-ups are sometimes seen as "parasites feeding off the innovative efforts of their parents, aided by 'vulture' capitalists that help them get started", alluding to the possibility of key employees leaving their employment to start their own firm in the same industry. Arguably, the threat of the establishment of a start-up can have a distorting effect on the incentives of incumbents to innovate.

This distortionary effect is amplified if the knowledge acquired by key employees is to a large extent tacit knowledge (see Polanyi (1966), Cowan et Al. (2000)) that can not be fully codified and therefore can only be imperfectly applied by the incumbent after the employee has left. An extensive empirical literature has shown that tacit knowledge is an important feature of highly innovative sectors, like the biotechnology industry (Zucker et Al. (1998)) and the computer industry (see Saxenian (1994) or Fallick et Al. (2006)).

Starting with Teece (1986), a number of authors have pointed out the importance of different types of complementary assets for the creation of new firms. Numerous examples of complementary assets, which are critical for the successful commercialization of new technologies, have been given in the literature. These include expertise and infrastructure for product development, manufacturing, legal, sales, distribution and customer service activities, as well as access to capital markets (see, e.g., Rothaermel and Deeds (2004), Rothaermel and Hill (2005), Park and Steensma (2012)). More precisely, Teece (1986) proposes a taxonomy that distinguishes between generic and specific complementary assets. The former need not be adjusted to the innovation and can frequently be contracted for in the market on competitive terms, whereas the latter need to be built over time, are often path dependent and idiosyncratic, and difficult to obtain in the market. Building on this taxonomy, recent empirical work (see, e.g., Rothaermel and Hill (2005)) has shown that industries differ substantially in terms of the nature of the needed complementary assets. Rothaermel and Hill (2005) establish that the computer industry and the steel industry rely mainly on generic complementary assets to commercialize new technologies, while the pharmaceutical industry (biotechnology) and the telecommunications industry (wireless telephony) rely mostly on specific complementary assets. For example, new entrants in the PC market do not need to rely on downstream assets of incumbents, such as their distribution channels. Rather they can easily find retail partners, like value-added resellers, in the market. Conversely, the commercialization of biotechnology innovations require regulatory knowledge and specialized sales competencies, which are available mainly at incumbent firms in the pharmaceutical industry (see again Rothaermel and Hill (2005)).

The trade-off between the ease of diffusion of knowledge and the incentives to invest in its generation is one of the main themes of the economics of innovation (Arrow (1962)). Understanding the outcome resulting from the instance of this trade-off described above is the main contribution of our paper and it has important implications for the assessment of the effects of the availability of complementary assets. In par- 
ticular, we characterize industry features such that an increase in the availability of complementary assets has negative vs. positive overall effects on generated knowledge, start-up formation, firms' profits, and employees' revenues.

Our framework builds on the three key features of innovative industries, such as the biotechnology and the computer industries, highlighted in the discussion above: start-up formation, the importance of tacit knowledge, and the need of complementary assets for the creation of new firms. An incumbent firm invests in $R \& D$ to generate new knowledge, which is embodied in a key employee (a positive externality increasing her outside options). The latter has the opportunity to found a start-up that competes with the incumbent in the same industry ${ }^{1}$. However, in order to create a start-up, the employee needs to have access to complementary assets, which are provided by third parties $^{2}$. If she leaves the firm to found a start-up, only a fraction of the knowledge generated through $R \& D$, which is partly tacit, remains with the incumbent. The firm then suffers a reduction in profits both because of its inability to fully appropriate the returns from R\&D investments, and because of the presence of a further competitor in the industry. In most of our analysis, we assume that the employee can not credibly commit ex ante not to leave the firm once she has acquired valuable knowledge. However, we explore the possibility of such a commitment at the end of Section 4, where we allow for the introduction of non-compete clauses ${ }^{3}$.

The value of the knowledge stock generated by $\mathrm{R} \& \mathrm{D}$ activities is common knowledge, so that the firm and the employee bargain over the size of the wage premium that the firm is willing to pay in order to prevent the employee from leaving. In case of disagreement, the employee leaves the firm (to found a start-up) and her payoff is determined through bargaining with a provider of key complementary assets. Hence, the value of the employee's outside option depends ultimately on the availability of these assets. On the one hand, by choosing the level of R\&D effort, the firm influences the employee's incentives to create a start-up, and therefore whether a new firm will form or not. On the other hand, R\&D expenses positively affect the incumbent's profits for a given market structure. The interplay of these two effects determines the investment decision of the firm, crucially depending on the availability of complementary assets.

If complementary assets in an industry are easily accessible the employee's outside option when negotiating employment conditions with the firm (given the employee's opportunity of founding a start-up) is of high value. Potentially, this leads to disagreement between the firm and the key employee (resulting in the formation of a start-up), or to a larger compensation for the employee if an agreement is reached. Both effects imply reduced incentives for the incumbent to invest in the accumulation of $\mathrm{R} \& \mathrm{D}$ knowledge.

\footnotetext{
${ }^{1}$ For one of the industry examples given above, the biotechnology industry, it has been pointed out in the literature that most start-ups in the infancy of the industry in the 1990s were University spin-offs. However, more recent evidence highlights that a large fraction of start-ups originate from incumbent firms in the industry, see Curran et $A l$. (2011).

${ }^{2}$ There are situations in which the needed complementary assets can be internally provided by the incumbent firm. We explore the possibility of a start-up forming as a spin-off of the incumbent firm in Section 5.

${ }^{3}$ The introduction of non-compete covenants is a natural instrument to gain such commitment. However, these covenants are not always enforceable (see, e.g., Fallick et Al. (2006)). See also Anton and Yao $(1994,1995)$ for a discussion of the many instances in which property rights over R\&D knowledge are weak or absent.
} 
Once a start-up is formed, however, the overall bargaining power of the employee when dealing with the provider of the complementary assets only affects the allocation of the start-up profits between the two, without influencing any longer the firm's innovative efforts. Hence, the incumbent's investment in R\&D knowledge is strictly decreasing for levels of complementary assets availability at which a start-up does not form, and it remains constant, although inefficiently provided, for higher degrees of complementary assets availability. Two sources of inefficiencies arise: ex ante, there is under-investment associated to the distortions in the incumbent's incentives to innovate; ex post, there is the possibility that no start-up is formed even if aggregate industry profits would rise should start-up formation occur ${ }^{4}$.

It is interesting to note that, although an increase in the availability of complementary assets harms the incumbent by improving the outside option of the key employee, the latter does not necessarily benefit from this increase. There are two opposite effects at work: a direct effect, implying that for a given level of R\&D knowledge an increase in the employee's outside options rises the fraction of the incumbent's profits she obtains; and a strategic effect, due to the decreasing incentives of the firm to invest in R\&D, which in turn reduces its profits. Taken together the direct and the strategic effects imply that the employee receives a larger fraction of a shrinking joint surplus, so that the larger availability of complementary assets can indeed harm the employee as well as the incumbent.

The paper is organized as follows. We discuss related literature in Section 2 and describe our model in Section 3. In Section 4 we derive our main results, investigating the influence of complementary assets on the investment in innovation by the incumbent firm, and the process of start-up formation. In Section 5 we extend our basic setup by introducing the possibility that the incumbent directly provides the complementary assets that are needed for the formation of a spin-off. Finally, in Section 6 we discuss our main results in relation to specific industries (e.g., computers and biotechnology), suggesting also testable empirical implications derived from our analysis. In Appendix A, we exemplify our general framework through a standard duopoly model with linear demand and quality improving $R \& D$ that helps developing an intuitive understanding of the key results. All figures in the paper have been produced using this example. Appendix B contains all proofs and technical details.

\section{$2 \quad$ Related Literature}

Besides the empirical literature on complementary assets briefly discussed in the Introduction, two other streams of research are closely related to our analysis. The first one looks at the role of tacit knowledge on entrepreneurship and innovative efforts of firms. The empirical literature in this field shows that the commercialization of innovative technologies (like biotechnology) is strongly affected by the fact that the underlying relevant knowledge is to a large extent tacit (see, e.g., Zucker et Al. (1998) ). On theoretical ground, the most closely related paper to ours is Spulber (2012), which explores the role of tacit knowledge for the trade-off between entrepreneurship and

\footnotetext{
${ }^{4}$ In Section 5 of the paper we show that in the cases in which a start-up forms as a spin-off of the incumbent firm ex post inefficiency is eliminated, while ex ante under-investment still arises.
} 
technology transfer. Spulber (2012) highlights how tacit knowledge affects the investment incentives of an inventor and an incumbent firm that have to decide whether to compete or to cooperate through technology transfer. His main finding is that in equilibrium higher quality inventions result in entrepreneurship, due to the fact that tacit knowledge cannot be fully transferred from the inventor to the firm. Our framework is substantially different than the one in Spulber (2012) in that in our setup the $\mathrm{R} \& \mathrm{D}$ employee gains (tacit) knowledge based on the $\mathrm{R} \& \mathrm{D}$ investment of the incumbent firm. Furthermore, again differently from Spulber (2012), we focus on the effects of the availability of complementary assets on entrepreneurship and investments. More generally, to the extent that in our framework the firm faces the risk of loosing part of the knowledge generated by its $R \& D$ investment, our contribution is also related to the debate on under-investment in general human capital stemming from Becker (1962)'s seminal contribution.

A second stream of related literature investigates the factors influencing if and how start-ups are formed. Several papers (see, e.g., Anton and Yao (1994, 2002), and Anand and Galetovic $(2000,2004)$ ) study different strategies to prevent, or to foster and finance, the formation of start-ups by employees of an incumbent firm. Most closely related to our setup are Anton and Yao (1995) and Baccara and Razin (2012). Anton and Yao (1995) investigate the formation process of spin-out firms (i.e., employees leaving the incumbent) and internal spin-offs (stemming from the revelation of an employee's ideas within the firm), analyzing the contractual negotiations between the employee and the incumbent both in an ex ante and in an ex post perspective. Baccara and Razin (2012) add the analysis of situations in which employees may decide not to reveal their ideas on new products to the incumbent (depending on the design of their ex ante contract). In particular, they study how imperfect property rights affect the incumbent's decision making and attitude towards innovation, and investigate the impact of information leakages during within-firm bargaining on outside options. While these papers carefully analyze different aspects of the start-up formation process with absent or weak property rights, they do not link them to the ex-ante incentives of firms to invest in innovative activities. In fact, all these papers assume that a fixed amount of R\&D investment is needed to develop an innovation, and hence do not directly focus on the level of R\&D investment by incumbents. Furthermore, the consideration of the search process for complementary assets distinguishes our approach from these papers. The explicit analysis of the effects stemming from the availability of complementary assets on ex ante R\&D investments and ex post bargaining between the incumbent and a key employee is indeed the main novel contribution of our paper ${ }^{5}$.

Finally, Franco and Filson (2006) study start-up formation focusing on the transmission of knowledge through employee mobility. In their framework, spin-out firms

\footnotetext{
${ }^{5}$ In our setup, ex-ante contracting has no role, because the object to be traded in the bargaining between the employee and the firm (i.e., the share of $R \& D$ knowledge embodied in the employee) is not ex-ante verifiable or contractible. The fact that ex-ante sharing rules do not influence ex-post bargaining if the traded object is not ex-ante contractible has been highlighted by Aghion and Tirole (1994). Furthermore, even if the R\&D knowledge were verifiable and hence ex-ante contractible, we could still restrict attention to ex-post bargaining without loss of generality. Indeed, ex-ante sharing rules have no impact on the outcome of the ex-post bargaining, because any ex-ante contract increasing the incumbent's investment incentives would be renegotiated ex-post, due to the fact that the employee cannot commit to stay in the firm.
} 
can be started by former employees of incumbents, who might 'pay' for the possibility of learning the know-how of their employers. This leads to Pareto optimal creation of new firms. As in our model, the innovation effort of firms is endogenous, but contrary to our contribution the effects of complementary assets for start-up formation are not studied. Gersbach and Schmutzler (2003b) and Gersbach and Schmutzler (2003a) analyze how potential spillovers through worker mobility affects firms' incentives for R\&D investments in Cournot and Bertrand duopolies, respectively. Similar to our approach it is assumed that the knowledge generated in a firm might be transferred to a competitor due to workers' mobility, which - like in our paper - depends on the wage offers workers' receive once they have acquired their knowledge. However, contrary to our setting, these papers focus on mobility between competitors rather than on the generation of start-ups, so that they do not investigate the effects of the availability of complementary assets, which is a distinguishing feature of our contribution.

\section{The Model}

We consider the interaction between a firm (F) and a key R\&D employee (E). The firm invests $I(K)$ in order to generate the new knowledge $K$ that is embodied in the employee. The employee may found a start-up company, which then competes with firm F. In order to do so, complementary assets are needed, which might be provided at a cost $C(K)$ by a third party, or by the firm $F$ itself. If no start-up is created the firm earns the monopoly profit $\pi_{F}^{m}(K)$. At least part of the knowledge of the employee is tacit, which implies that after she left the firm to establish a start-up, only a fraction of her knowledge stock can be exploited by the incumbent firm. We denote the profit earned by the incumbent in this case with $\pi_{F}^{s}(K)$, and that of the start-up founded by the employee, gross of the costs of complementary assets, with $\pi_{E}^{s}(K)^{6}$. We assume that $\pi(0)=0, \pi^{\prime}(K)>0$, for all $K \geq 0$, and $\pi=\pi_{F}^{m}, \pi_{F}^{s}, \pi_{E}^{s}$. The strategic incentives of the incumbent and of the employee are analyzed in a three-stage framework (see Figure 1).

Stage 1. In the first stage, the firm chooses the stock of knowledge $K$ to be generated, bearing the costs $I(K)$. In order to guarantee positive optimal investment and the convexity of the industry profits with respect to $K$, we make the following assumption on the shape of the cost function for generating knowledge.

\section{Assumption 1}

$$
\begin{aligned}
I^{\prime}(K) & >0, I^{\prime}(0)<\pi_{F}^{s}(0) \\
I^{\prime \prime}(K) & \geq \max \left\{\frac{\partial^{2}\left(\pi_{F}^{s}(K)+\pi_{E}^{s}(K)-C(K)\right)}{\partial K^{2}}, \frac{\partial^{2} \pi_{F}^{m}(K)}{\partial K^{2}}\right\} .
\end{aligned}
$$

\footnotetext{
${ }^{6}$ Throughout the paper the superscript $s$ refers to variables corresponding to the situation in which a start-up is created, whereas $m$ refers to the case in which the employee remains employed at the firm. Also, we use the subscript $E$ to denote the profit earned by the start-up founded by the employee, although parts of this profit is allocated to the provider of the complementary assets.
} 


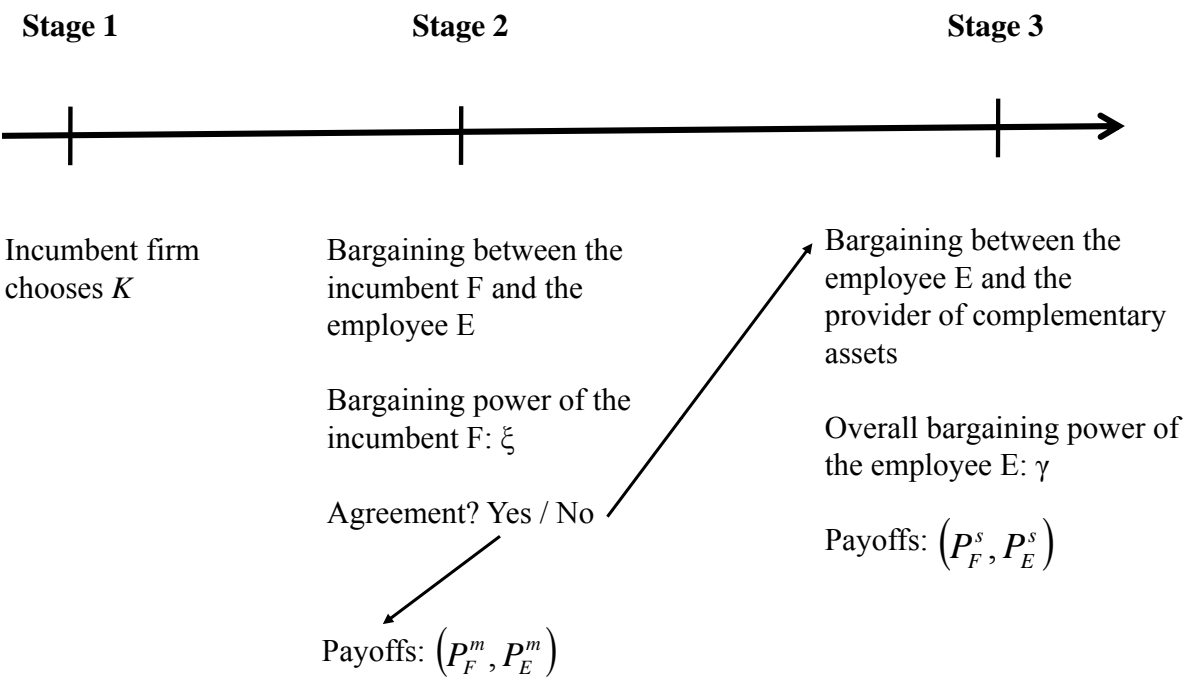

Figure 1: The structure of the multi-stage interaction.

Stage 2. In the second stage, the size of the knowledge stock $K$ is common knowledge. The firm and the employee bargain over the size of a wage bonus that the latter receives from the firm if she does not create a start-up. If this bargaining results in disagreement, the employee leaves the firm and payoffs are determined according to the interaction described in stage 3 . Therefore, disagreement in stage 2 results if the total payoff of both sides in case of start-up formation is larger than the total payoff achieved when a start-up is not formed. If there is agreement in stage 2, then the bargaining outcome is determined according to a generalized Nash bargaining solution, where the bargaining power of the firm is denoted by $\xi \in(0,1)^{7}$.

Stage 3. If there is disagreement in stage 2, the employee leaves the firm and her payoff is determined through bargaining with a provider of the complementary assets needed to create a start-up. If the (former) employee is not able to obtain the necessary complementary assets from the current negotiation partner, she has to find another provider. This needs search time, and therefore the payoff earned by the employee after the search has to be discounted by a factor $\alpha \in(0,1)$. The larger the number of potential providers of the needed complementary assets is, the shorter is the necessary search time, and the larger is $\alpha$. As for the bargaining in stage 3, we assume that the outcome of the bargaining, which determines the distribution of the start-up ownership between the founder and the provider of the necessary assets, is given by a generalized Nash bargaining solution, where $\beta \in(0,1)$ denotes the bargaining power of the em-

\footnotetext{
${ }^{7}$ Note that the interaction between the firm and the employee in stage 2 could be equivalently modeled as a non-cooperative game where one side makes an offer and the other side can accept or reject it, like in an ultimatum game. In this formulation, $\xi$ would denote the probability that the firm makes the offer. For simplicity of exposition, we stick to the reduced form Nash bargaining formulation, which yields exactly the same outcome.
} 
ployee. We denote by $x$ the amount allocated to the employee in the bargaining and we assume for simplicity that all potential alternative providers are identical. Thus, considering that the provider of the complementary assets saves the cost $C(K)$ in case of disagreement, the threat-points of the start-up's founder and of the provider are $\alpha x$ and $C(K)$, respectively. The joint surplus to be allocated is $\pi_{E}^{s}(K)$. Accordingly, we get

$$
x=\alpha x+\beta\left(\pi_{E}^{s}(K)-C(K)-\alpha x\right),
$$

and hence

$$
x=\frac{\beta}{1-\alpha(1-\beta)}\left(\pi_{E}^{s}(K)-C(K)\right) .
$$

Given that the employee has to search for a provider of complementary assets when deciding to found a start-up, she expects the payoff

$$
\alpha x=\gamma\left(\pi_{E}^{s}(K)-C(K)\right),
$$

where

$$
\gamma=\frac{\alpha \beta}{1-\alpha(1-\beta)} \in(0,1)
$$

measures the overall bargaining power of the start-up founder when dealing with a provider of complementary assets. The parameter $\gamma$ is the key parameter of our analysis $^{8}$. The term $(1-\gamma)$ measures the fraction of generated profits that the start-up founder has to give up in order to get access to the complementary assets needed for the commercialization of her product. Note that, recalling the discussion in Section 2, $\gamma$ is likely to be small if the needed complementary assets are specific. Furthermore, whereas the specificity of the needed complementary assets is typically determined by the characteristics of the considered industry, also regional differences might influence $\gamma$. In particular, the absence of a local industry base in the neighborhood of firm $F$ makes it more difficult to find (local) providers of the needed complementary assets, which might imply a small value of $\gamma$.

In order to ease the exposition, we define $\Delta \pi_{F}$ as the loss in profits of the incumbent when a start-up is formed, and $\Delta \pi_{E}$ as the net profit of the start-up; i.e.,

$$
\begin{array}{lll}
\Delta \pi_{F}(K):= & \pi_{F}^{m}(K)-\pi_{F}^{s}(K), \\
\Delta \pi_{E}(K):= & \pi_{E}^{s}(K)-C(K) .
\end{array}
$$

We make the following assumption on $\Delta \pi_{E}$ and $\Delta \pi_{F}$.

\section{Assumption 2}

$$
\begin{aligned}
\Delta \pi_{E}(K) & >\Delta \pi_{F}(K)>0, \\
\Delta \pi_{E}^{\prime}(K) & >\Delta \pi_{F}^{\prime}(K)>0 \forall K>0 .
\end{aligned}
$$

This amounts to assuming that the creation of a start-up harms the incumbent, and that the marginal return on additional knowledge for the incumbent is always positive

\footnotetext{
${ }^{8}$ Although all our results will be formulated in terms of $\gamma$, the fact that $\gamma$ is monotonically increasing in $\alpha$ permits to immediately interpret all our findings also in terms of the fundamental parameter $\alpha$ capturing the expected search time of the start-up founder.
} 
and larger if the employee remains with the firm than if she creates a start-up. Also, since our focus is on the impact of the threat of start-up formation on the investment incentives of the incumbent, we let the net profits of a start-up be positive and larger than the losses suffered by the incumbent ${ }^{9}$. Moreover, this effect becomes stronger the larger the knowledge stock of the employee is.

\section{$4 \quad$ R\&D Investment and Start-Up Formation}

The main goal of our analysis is to investigate the strategic effect of the availability of complementary assets on firm investment and start-up formation. As a preliminary step, we characterize the outcomes of stages 2 and 3 that determine the investment incentives in stage 1, through the following Lemma. To state the Lemma, we define

$$
G(K ; \gamma):=-\Delta \pi_{F}(K)+\gamma \Delta \pi_{E}(K),
$$

and let $\hat{K}$ be the set of $K$ values such that, for all $K \in \hat{K}$, one has $G(K ; \gamma) \leq 0$.

\section{Lemma 1}

(i) A start-up forms if and only if $K \notin \hat{K}$;

(ii) the payoff of the incumbent firm is given by

$$
P_{F}(K ; \gamma)=\left\{\begin{array}{ll}
P_{F}^{m}(K ; \gamma)=\pi_{F}^{s}(K)-I(K)-\xi G(K ; \gamma) & \text { if } K \in \hat{K} \\
P_{F}^{s}(K)=\pi_{F}^{s}(K)-I(K) & \text { otherwise }
\end{array} ;\right.
$$

(iii) the payoff of the employee is given by

$$
P_{E}(K ; \gamma)=\left\{\begin{array}{ll}
P_{E}^{m}(K ; \gamma)=\Delta \pi_{F}+\xi G(K ; \gamma) & \text { if } K \in \hat{K} \\
P_{E}^{s}(K ; \gamma)=\gamma \Delta \pi_{E} & \text { otherwise }
\end{array} .\right.
$$

The function $G(K ; \gamma)$ measures the increase in the joint net profits of the incumbent and of the start-up in case of start-up formation ${ }^{10}$. The employee creates a new firm if and only if the joint profit increase $G(K ; \gamma)$ is positive.

Efficient Investment Benchmark. Before characterizing the R\&D investment of the firm, we derive the efficient investment level to be used as a benchmark in the subsequent analysis. By Assumption 2, overall market profits are always larger when a start-up forms. Accordingly, with a slight abuse of notation, we denote the creation of a new firm as the efficient outcome. The corresponding efficient investment level is given by

$$
K^{e f f}=\arg \max _{K}\left[\pi_{F}^{s}(K)+\Delta \pi_{E}^{s}(K)-I(K)\right] .
$$

\footnotetext{
${ }^{9}$ If this assumption is violated the bargaining between the incumbent and the employee cannot lead to disagreement and no start-up is formed. Therefore, qualitatively the resulting outcomes would exactly correspond to those characterized below for values of $\gamma$ at which no start-up is created.

${ }^{10}$ We explicitly indicate the dependence of $G$ on $\gamma$ since our analysis focuses on variations of $\gamma$.
} 
In this benchmark, the firm fully internalizes the profits of the start-up, which removes both types of inefficiencies present in our setup. An instrument to remove the ex-ante inefficiency, resulting from the distortion of the investment incentives of the firm due to potential start-up formation, is the introduction of non-compete clauses. However, it has been argued (see, e.g., Franco and Filson (2006), and Anton and Yao (1995)) that such clauses are only partially effective in many industries. Therefore, most of our analysis will rely on the assumption that workers cannot commit ex-ante not to leave the firm. At the end of this section, we will extend our analysis in order to compare our results with those that would emerge when non-compete clauses prevent the worker from founding a start-up competing with the incumbent firm.

Optimal Investment and Start-Up Formation. We now turn to the determination of the optimal choice of $K$ by the incumbent in stage 1 and the induced pattern of startup formation. The presence of a provider of complementary assets - by allowing the creation of a start-up - implies that the incumbent firm on the margin acquires less than the full return on investment. Hence, one would expect a downward distortion in its investment incentives.

Under Assumption $1, P_{F}^{m}(K ; \gamma)$ and $P_{F}^{s}(K)$ are strictly concave functions. Note further that $K \in \hat{K}$ if and only if $P_{F}^{m}(K ; \gamma) \geq P_{F}^{s}(K)$. Therefore, at stage 1 , the incumbent maximizes over the upper envelope of $P_{F}^{m}$ and $P_{F}^{s}$.

We define

$$
\bar{K}_{m}(\gamma)=\underset{K}{\arg \max } P_{F}^{m}(K ; \gamma)>0, \quad \bar{K}_{s}=\underset{K}{\arg \max } P_{F}^{s}(K)>0,
$$

as the optimal investment levels when a start-up does not form and when it forms, respectively. Note that Assumption 1 guarantees that the argmax are positive and that $P_{F}^{s}(K)$, and hence also $\bar{K}_{s}$, are independent of $\gamma$. Furthermore, we define

$$
K^{*}(\gamma)=\underset{K}{\arg \max } P_{F}(K ; \gamma),
$$

as the optimal level of the incumbent's R\&D investment, where $P_{F}$ is given in Lemma 1. It is easy to see that

$$
K^{*}(\gamma) \in\left\{\bar{K}_{m}(\gamma), \bar{K}_{s}\right\}
$$

Note that, on the one hand, by choosing $K$ the firm influences the employee's incentives to create a new firm, and therefore whether a start-up forms or not. On the other hand, $K$ affects the incumbent's profits for a given market structure. The interplay of these two effects determines the optimal investment, which crucially depends on the bargaining power of the employee with the provider of the needed complementary assets, $\gamma$.

The following Proposition characterizes the optimal knowledge investment of the incumbent, as well as the resulting pattern of start-up formation for different values of $\gamma$

\section{Proposition 2}

(i) There exists a unique value $\bar{\gamma} \in(0,1]$ such that the optimal level of knowledge 
investment is $K^{*}(\gamma)=\bar{K}_{m}(\gamma)$ for all $\gamma<\bar{\gamma}$, and $K^{*}(\gamma)=\bar{K}_{s}$ for all $\gamma>\bar{\gamma}$. No start-up formation occurs for all $\gamma<\bar{\gamma}$, while a start-up is formed for all $\gamma>\bar{\gamma}$.

(ii) $\frac{\partial K^{*}(\gamma)}{\partial \gamma}<0$ for all $\gamma<\bar{\gamma}$, and $\frac{\partial K^{*}(\gamma)}{\partial \gamma}=0$ for all $\gamma>\bar{\gamma}$.

(iii) For all $\gamma, K^{*}(\gamma)<K^{e f f}$.

The proposition illustrates the effects of the availability of complementary assets on the firm's R\&D effort. If complementary assets are easy to access (large $\gamma$ ), then the employee's outside option when negotiating employment conditions with the firm (given the employee's opportunity of founding a start-up) is high. This has three potential effects: first, it increases the possibility of disagreement, which results in the establishment of a start-up (see part (i) of Proposition 2); second, it increases the compensation that the employee receives from the firm in the case of agreement (see part (iii) of Lemma 1); and third, it reduces the firm's incentives to invest in the generation of new knowledge. The last effect is formally illustrated by the observation that $\bar{K}_{m}(\gamma)$ is decreasing in $\gamma$ (see part (ii) of Proposition 2). Note, however, that when a start-up is created, then $\gamma$ only influences the net surplus allocation between the employee and the provider of complementary assets; hence, the incumbent's incentives to invest in $\mathrm{R} \& \mathrm{D}$ are independent of $\gamma$ (i.e., $\bar{K}_{s}$ is constant in $\gamma$ ). The third part of the proposition shows that, no matter whether a start-up is formed or not, the firm's incentives to invest fall short of the efficient benchmark due to the fact that part of the total surplus generated by start-up formation is not appropriated by the firm. This is reminiscent of Becker's (1962) classical result on firms' under-investment in general human capital.

Increasing and Decreasing Knowledge Effects. We can now investigate how the incentives to invest in $\mathrm{R} \& \mathrm{D}$ in the start-up case compare with those in the case in which the firm retains the employee. Intuition might suggest that the firm's incentives to invest are larger if no start-up is formed and all the knowledge generated stays within the incumbent firm. In what follows, we characterize under which circumstances the inequality $\bar{K}_{m}(\gamma)>\bar{K}_{s}$ is indeed satisfied. In order to do so, we distinguish between two situations. Denote by $\epsilon_{F}(K)$ the elasticity of the incumbent's losses due to start-up formation with respect to $K$, and by $\epsilon_{E}(K)$ the elasticity of the start-up's profits with respect to $K$; i.e.,

$$
\epsilon_{F}(K)=\frac{\Delta \pi_{F}^{\prime}(K) K}{\Delta \pi_{F}(K)}, \epsilon_{E}(K)=\frac{\Delta \pi_{E}^{\prime}(K) K}{\Delta \pi_{E}(K)} .
$$

The relative size of these elasticities turns out to be closely related to the way in which the generation of new knowledge $(K)$ influences overall market profit gains induced by the formation of a start-up. In particular, if the total industry profit gains from start-up formation $\left(\Delta \pi_{E}-\Delta \pi_{F}\right)$ increase with $K$ in an elastic way (which holds true in particular for all convex profit gains functions), then $\epsilon_{F}(K)<\epsilon_{E}(K)$ for all $K>0$ (see Lemma 7 in Appendix B). As it can be seen from the dashed line in Panel (a) of Figure 2 , this elasticity property implies that the net profit gains from start-up formation are very small for low levels of $K$. Qualitatively, one can note that for industries in which $\epsilon_{F}(K)<\epsilon_{E}(K)$ for all $K>0$, a relatively high level of knowledge is needed before 


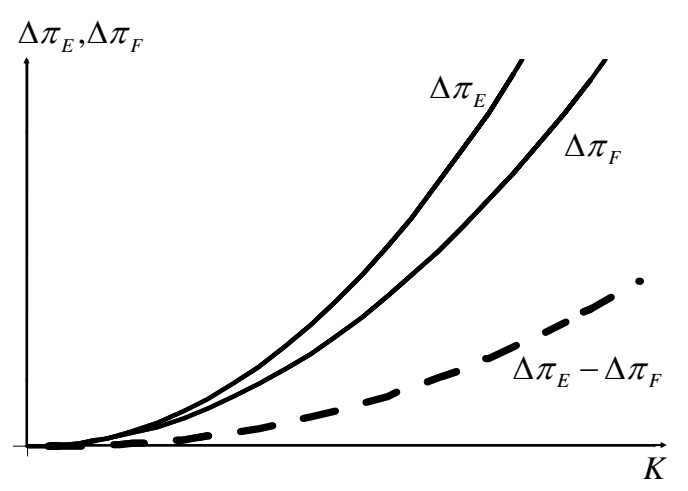

(a)

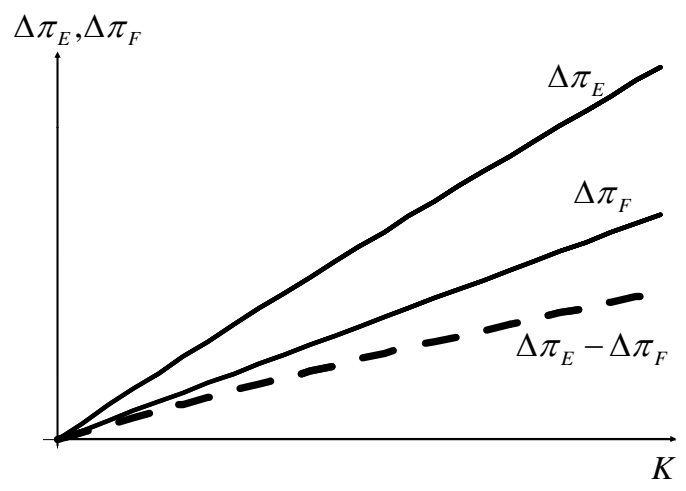

(b)

Figure 2: Effect of R\&D investments on $\Delta \pi_{F}$ and $\Delta \pi_{E}$ in case of increasing (a) and decreasing (b) knowledge effects.

the creation of a start-up generates a substantial profit gain. Accordingly, we say that there is an increasing knowledge effect on industry profit gains implied by start-up formation - and for notational convenience we label the cases in which $\epsilon_{F}(K)<\epsilon_{E}(K)$, for all $K>0$, as being characterized by an increasing knowledge effect. Conversely, if $\epsilon_{F}(K)>\epsilon_{E}(K)$ for all $K>0$, then the function representing profit gains from startup formation $\left(\Delta \pi_{E}-\Delta \pi_{F}\right)$ is increasing in $K$ and everywhere inelastic. As shown in Panel (b) of Figure 2, this property implies that there are relevant effects of knowledge generation on profit gains already for low levels of $K$, but the marginal effects of additional knowledge become smaller as knowledge increases. For large levels of $K$, total industry profit gains from start-up formation are almost constant with respect to $K$, which means that an increase in knowledge has almost the same effect on total industry profit for the cases with and without start-up formation. In the following, we refer to the industries in which $\epsilon_{F}(K)>\epsilon_{E}(K)$ for all $K>0$ as being characterized by a decreasing knowledge effect.

To gain a better intuition for the factors that determine whether there are increasing or decreasing knowledge effects, consider a scenario in which all profit functions under different market structures (i.e., $\pi_{F}^{m}, \pi_{F}^{s}, \pi_{E}^{s}$ ) share the same constant elasticity with respect to $K$. This scenario may easily occur in standard oligopoly models, as it is shown in Appendix A, where we consider a Cournot oligopoly in which consumers have quality augmented quadratic utility functions and R\&D leads to quality improvements. Knowledge effects are increasing if the elasticity of market profits is larger than the elasticity of the start-up costs $C(K)$ with respect to $K$. Intuitively, this means that the additional market profits originating from the creation of a start-up are more elastic than the costs of setting up the start-up. Therefore, the profit gains from start-up formation increase in a convex way with $K$. Furthermore, since only the payoff of the start-up is affected by the costs $C(K)$, the elasticity of $\Delta \pi_{E}$ is smaller than that of $\Delta \pi_{F}$. Hence, the relative magnitude of the elasticity of market profits versus startup costs essentially determines whether decreasing or increasing knowledge effects are observed, as well as the sign of $\epsilon_{E}(K)-\epsilon_{F}(K)$. 


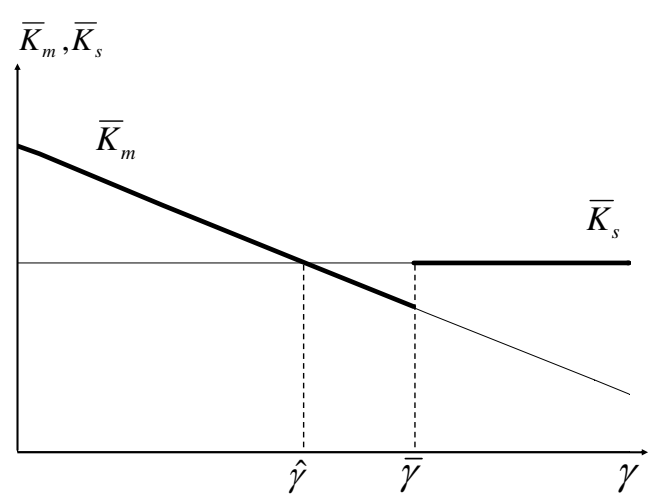

(a)

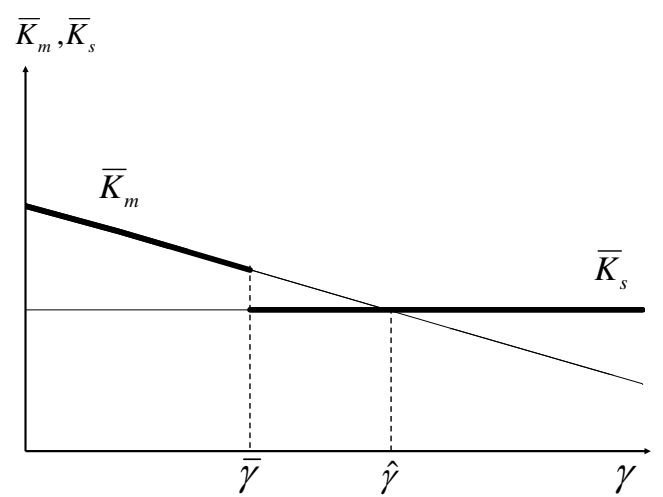

(b)

Figure 3: Optimal R\&D investment for varying availability of complementary assets $(\gamma)$ in the cases of increasing (a) and decreasing (b) knowledge effects of investment.

The following proposition shows that, on the one hand, under increasing knowledge effects, complementary assets must be easy to access in order to foster the creation of a new firm. Furthermore, the optimal investment level of a firm that is able to prevent the employee from leaving can be lower than the level that would be optimal if a start-up forms. On the other hand, under decreasing knowledge effects, the minimal availability of complementary assets that leads to the creation of a new firm is relatively small, and the optimal investment level in the cases in which a start-up is founded is always smaller than that in the cases in which the employee remains employed at the firm.

\section{Proposition 3}

(i) There exists a unique $\hat{\gamma} \in(0,1)$ such that $\bar{K}_{m}(\hat{\gamma})=\bar{K}_{s}$.

(ii) If there are increasing knowledge effects, then $\bar{\gamma}>\hat{\gamma}$ and for all $\gamma \in(\hat{\gamma}, \bar{\gamma})$ no start-up is created but the RED investment of the incumbent is below the optimal investment under start-up formation: $\bar{K}_{m}(\gamma)<\bar{K}_{s}$ for all $\gamma \in(\hat{\gamma}, \bar{\gamma})$. The optimal investment $K^{*}(\gamma)$ exhibits an upward jump at $\gamma=\bar{\gamma}$.

(iii) If there are decreasing knowledge effects, then $\bar{\gamma}<\hat{\gamma}$. Whenever a start-up is not formed, the RED investment of the incumbent is above the optimal investment under start-up formation: $\bar{K}_{m}(\gamma)>\bar{K}_{s}$ for all $\gamma \leq \bar{\gamma}$. The optimal investment $K^{*}(\gamma)$ exhibits a downward jump at $\gamma=\bar{\gamma}$.

Figure 3 illustrates Proposition 3. The upward jump depicted in Figure 3(a) might be surprising at first, considering that for $\gamma<\bar{\gamma}$ the incumbent retains all generated knowledge in the firm, while for $\gamma>\bar{\gamma}$ it partly looses it. To gain an intuition for this finding, note that start-up formation occurs only if the induced increase in industry profits is large enough to account for the profit share accruing to the provider of the complementary assets. In the case of increasing knowledge effects, the additional industry profit at the optimal investment level is relatively small compared to the case of a decreasing knowledge effect (see Figure 2). Hence, for a large range of values of 
$\gamma$, additional profits can not account for the profit share of the provider of the complementary assets, and no start-up is formed. This implies that the main effect of an increase of $\gamma$ is an improvement of the employee's position in the bargaining process with the incumbent, which discourages the R\&D investment of the latter. Such a negative incentive effect occurs for a wider interval of values of $\gamma$ than under decreasing knowledge effects. In fact, under increasing knowledge effects, $\bar{\gamma}$ is so large that (at $\bar{\gamma})$ the negative incentive effect outweighs the direct effect of knowledge loss stemming from the creation of a start-up. Hence, as at $\bar{\gamma}$ the incumbent anticipates the creation of a start-up, its incentives to invest in $\mathrm{R} \& \mathrm{D}$ increase. The opposite occurs under decreasing knowledge effects, since in this case (as $\bar{\gamma}$ is small) the range of values of $\gamma$ such that no start-up forms is so small that the direct effect of knowledge loss dominates.

Observe that Propositions 2 and 3 together imply that $K^{*}(\gamma)<\bar{K}_{m}(0)$ for all $\gamma \in(0,1]$, where $\bar{K}_{m}(0)$ is the efficient level of R\&D investment for all levels of $\gamma$ for which no start-up is formed. Moreover, it follows from Assumption 2 that the efficient level of $K$ is even larger than $\bar{K}_{m}(0)$ when a start-up is formed. Therefore, there is always under-provision of $R \& D$ effort by the incumbent, regardless of whether a startup is generated or not.

Firm and Employee Payoffs. We finally turn to the relationship between profits and the availability of complementary assets. We denote with $P_{F}^{*}(\gamma)$ and $P_{E}^{*}(\gamma)$ the sets of payoffs of the firm and of the employee resulting from the optimal investment choice of the firm. In general, $P_{F}^{*}(\gamma)$ and $P_{E}^{*}(\gamma)$ are correspondences, but Lemma 8 in Appendix B establishes that these correspondences are almost everywhere single-valued and continuous. The following proposition characterizes the profits of the incumbent and of the start-up's founder with respect to the availability of complementary assets.

\section{Proposition 4}

(i) The profits of the incumbent firm are strictly decreasing in $\gamma$ for $\gamma<\bar{\gamma}$ and constant in $\gamma$ otherwise.

(ii) The profits of the employee are strictly increasing in $\gamma$ for the range of $\gamma$-values where a start-up is formed.

(iii) If knowledge has a decreasing effect then the employee's profits exhibit a downward jump for increasing $\gamma$ at $\gamma=\bar{\gamma}$.

There is a clear economic intuition for Proposition 4. When a start-up is formed, the profits and the investment level of the incumbent are unaffected by $\gamma$, since this parameter does not determine the size of the start-up's profits, but only their allocation between the provider of complementary assets and her founder. Given that the incumbent's investment level does not change upon the creation of the start-up, the profits of the start-up's founder are obviously increasing as her bargaining power with the provider of the required complementary assets increases. On the contrary, if no start-up is created, $\gamma$ affects the value of the employee's outside option when bargaining with the firm, and the profits of the latter are strictly decreasing in $\gamma$. The fact that the payoff of the firm is decreasing in $\gamma$ does not necessarily imply that the employee profits from an easier access to complementary assets. Two effects are at work: 


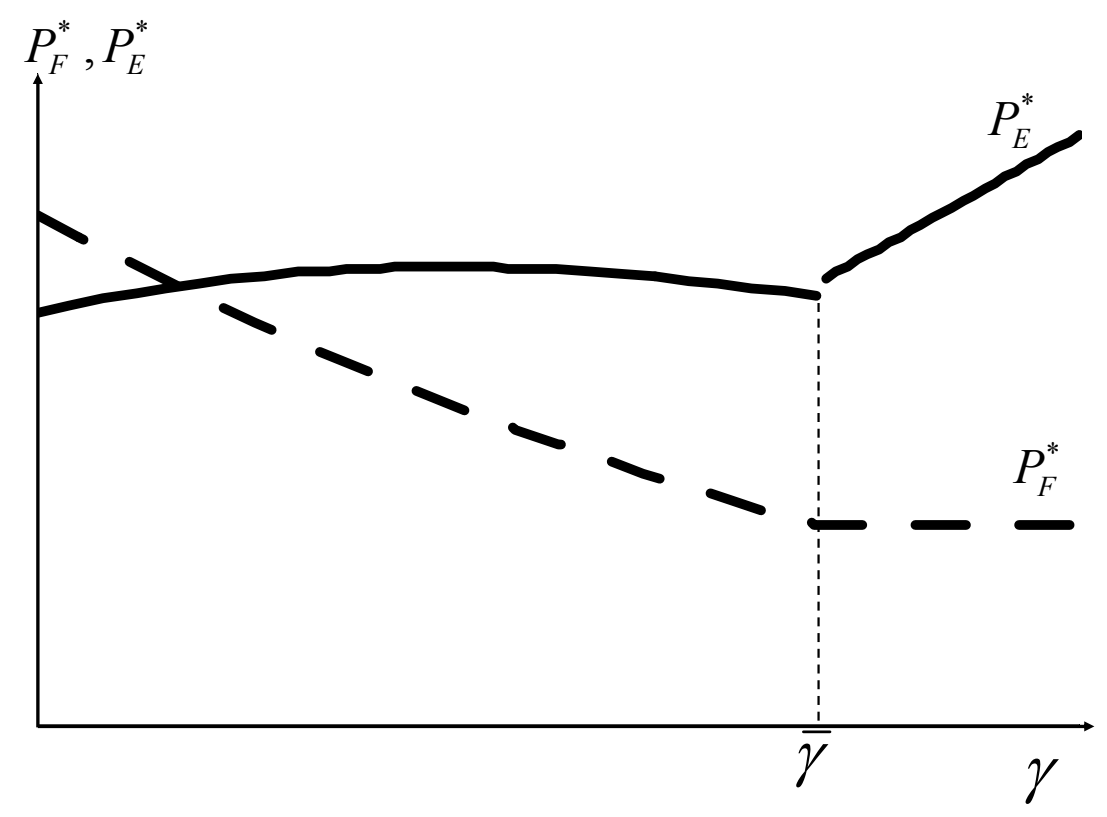

Figure 4: Firm's and employee's profits for varying availability of complementary assets $(\gamma)$ in the case of increasing knowledge effects of investment.

(i) a direct effect, implying that for a given level of $K$ an increase in the employee's outside option raises the fraction of the firm's profits $\pi_{F}^{m}(K)$ she obtains; (ii) an indirect strategic effect, due to the fact that as $\gamma$ increases the incentives of the firm to invest in R\&D, and accordingly its profits $\pi_{F}^{m}(K)$, diminish. Together, the direct and the strategic effects imply that the employee receives a larger fraction of a shrinking joint surplus, so that the net effect can be negative and a larger availability of complementary assets can harm the employee. Although for low and high values of $\gamma$ the employee's payoff rises if the availability of complementary assets increases, there is an intermediate interval of values of $\gamma$ in which increasing $\gamma$ exerts a negative effect on $P_{E}^{*}(\gamma)$. Since the incumbent's profits are strictly decreasing in $\gamma$, making the access to complementary assets more difficult would induce an increase in the profits of both the incumbent and the employee in that range. This effect is illustrated in Figure 4, from which it is also evident that, when knowledge has an increasing effect, raising $\gamma$ across the threshold $\bar{\gamma}$ might induce an upward jump of the employee's profits. Contrary to the case in which knowledge has a decreasing effect (see part (iii) of Proposition 4), however, the direction of the jump in the employee's profits can not be determined in general.

When knowledge has a decreasing effect, the relevance of the indirect strategic effect becomes particularly apparent if the parameter $\gamma$ moves from the range in which no start-up forms to the start-up region. In this case, in fact, the strategic effect induces a downward jump in the firm's R\&D effort that, as it is shown by the third claim of Proposition 4, results in a discontinuous reduction of the employee's payoff. 
Non-Compete Clauses. Although ex post, given the investment in $R \& D$ by the incumbent, the employee has an incentive to establish her own firm, one may conjecture that the employee could be better off by committing ex-ante not to form a start-up. However, such a commitment would affect the bargaining between the employee and the incumbent determining the employee's wage bonus. To further explore this issue we conclude the section by investigating the effect of the introduction of a non-compete clause preventing the employee from working in the same industry if she leaves the incumbent firm ${ }^{11}$. In order to ease the analysis, we also assume that the employee cannot profit from the knowledge she gains through the firm's R\&D investment in an alternative industry, so that her payoff upon leaving is given by $\pi_{E}^{s}(0)=0$, regardless of the chosen value of $K$. If the employee leaves the incumbent, the firm still remains the monopolist in the market, but its knowledge is reduced to $\delta K$. As a consequence, the bargaining between the employee and the firm as well as the firm's investment incentives are influenced by the existence of the non-compete clause. The following proposition shows that the existence of a non-compete clause positively affects the R\&D investment and the profits of the firm.

\section{Proposition 5}

Assume that the employee is committed to a non-compete clause and that $\delta \pi_{F}^{m \prime}(\delta K)>$ $\pi_{F}^{s}(K)$. Denote by $K^{n c *}$ the optimal RED investment and by $P_{F}^{n c *}$ and $P_{E}^{n c *}$ the corresponding payoffs of the incumbent and of the employee, respectively.

(i) The bargaining between the firm and the employee never results in disagreement.

(ii) $K^{n c *}>K^{*}(\gamma) \forall \gamma \in[0,1]$

(iii) $P_{F}^{n c *}>P_{F}^{*}(\gamma) \forall \gamma \in[0,1]$.

The assumption that $\delta \pi_{F}^{m \prime}(\delta K)>\pi_{F}^{s}{ }^{\prime}(K)$ captures the natural idea that the marginal effect of an increase in $K$ for firm $\mathrm{F}$ is larger if it is a monopolist with knowledge $\delta K$ compared to the case in which it is a duopolist with the same knowledge $\delta K$ and the knowledge of the competitor is $K$. This is a standard feature of oligopoly models, which holds also for the linear specification described in Appendix A. There is a clear intuition for Proposition 5. In the presence of a non-compete clause, two of the effects negatively affecting the incumbent's investment incentives are absent. First, since the the employee does not profit from $K$ when leaving the firm, her threat-point in the bargaining with the incumbent is not increasing in $K$, contrary to what it would be in the absence of the non-compete clause. Second, because the incumbent remains a monopolist for any $\gamma$, it benefits from a larger marginal effect of $K$ on profits than it would if the employee were to found a competing start-up. Hence, both the investment in $\mathrm{R} \& \mathrm{D}$ and the profits of the incumbent are larger under a non-compete clause than under the threat of start-up formation. Concerning the payoff of the employee, no general statements about the effect of the non-compete clause can be made. Although it is easy to see that for a given level of investment the weakening of her threat-point and

\footnotetext{
${ }^{11}$ We abstract here from any potential bargaining between the incumbent and the employee over the distribution of the surplus generated by the adoption of the non-compete clause.
} 
the inability to profit from the knowledge by starting a new firm is costly for the employee, she profits from the increase in $\mathrm{R} \& \mathrm{D}$ investment triggered by the non-compete clause. Which of these effects dominates depends on the details of the model.

\section{Start-Ups as Spin-Offs of the Incumbent}

In the analysis developed so far, three different parties are involved in the start-up formation process: the incumbent firm, the key employee and an external provider of complementary assets. The latter is needed to realize the potential benefits associated to the formation of the start-up, but his presence negatively influences the results of the bargaining between the incumbent and the employee in the sense that for $\gamma<\bar{\gamma}$ no start-up is formed although total industry profits would be higher in the presence of a start-up. In the following, we explore whether the efficiency of the start-up formation process can be improved if no third party is involved. In order to address this issue, we consider a situation in which the incumbent is able and willing to directly provide the needed complementary assets to the employee. The resulting start-up is therefore a spin-off of the incumbent firm. In this case, the employee has the option to bargain with the incumbent the conditions of spin-off formation, instead of having to turn necessarily to an external provider of complementary assets. For analytical simplicity, we assume that the firm and any external provider face exactly the same cost $C(K)$ to provide the required complementary assets. To incorporate the option that the firm can enable a spin-off, we alter the bargaining between the firm and the employee in such a way that the agreement between the two can lead either to no spin-off formation with a bonus for the employee, or to the generation of a firm-enabled spin-off in which the employee obtains a certain fraction of the profits. Which of these two options is chosen depends on the relative size of the joint surplus that is generated.

Recall from Section 3 that the bargaining power of the firm is given by $\xi$. In stage 2 of the altered bargaining game, the outside options of the firm and of the employee are again $P_{F}^{s}(K)$ and $P_{E}^{s}(K)$, respectively. However, based on our considerations above, the joint surplus is now given by

$$
S=\max \left[\pi_{F}^{m}(K)-I(K), \pi_{F}^{s}(K)-I(K)+\Delta \pi_{E}(K)\right] .
$$

Since by Assumption 2 total industry profits are larger if a start-up (spin-off) is formed, the maximum in the expression above is always attained for the case of spin-off formation, so that

$$
S=\pi_{F}^{s}(K)-I(K)+\Delta \pi_{E}(K) .
$$

It is easy to see that $S$ always exceeds the sum of the outside options. Hence, a spin-off forms, and the amount allocated to the firm in the Nash bargaining solution is given by $\tilde{P}_{F}^{s}(K ; \gamma)$, with

$$
\tilde{P}_{F}^{s}(K ; \gamma)=\pi_{F}^{s}(K)+\xi(1-\gamma) \Delta \pi_{E}(K)-I(K) .
$$

Accordingly, the optimal investment level of the firm in the case in which it has the 
resources to support a spin-off is

$$
\tilde{K}_{s}=\underset{K}{\arg \max } \tilde{P}_{F}^{s}(K ; \gamma) .
$$

In the following proposition, we compare optimal investment levels and spin-off formation conditions under internal provision with the case of external provision of complementary assets, and with our efficiency benchmark.

\section{Proposition 6}

(i) Given that spin-off formation is efficient, then it always occurs under internal provision of the required complementary assets.

(ii) The optimal level of RED effort with internal provision of complementary assets is strictly decreasing in $\gamma$ and always larger than the optimal level of R\&D without internal provision, but lower than the efficient level $K^{\text {eff }}$.

As it is to be expected, the possibility of internal provision improves the efficiency properties of the outcome. More precisely, the efficient outcome in terms of spin-off formation is reached, and the investment level increases compared to the scenario in which the incumbent lacks the assets to enable a spin-off. However, investment falls short of the efficient amount.

With the option of internal provision of complementary assets the firm and the employee can freely decide upon the market structure without loosing any of the industry profits to a third party. Hence, they always choose the efficient structure, which in our case is one with spin-off formation. When the potential start-up has to rely on an external provider of complementary assets, choosing to form a start-up implies a loss of part of the overall surplus to a third party, and therefore the firm and the employee may agree not to do so even if their choice is not efficient.

There are two reasons for an inefficient level of investment to arise. First, even with internal provision, the firm appropriates only a fraction $\xi$ of the generated overall surplus; a problem that remains unresolved also when internal provision is allowed for. Second, investment improves the outside options of the employee, causing a reduction of the incumbent's incentives to invest ex ante, and hence reducing the net surplus. It is worth stressing that the latter effect is stronger the larger is the availability of complementary assets, which explains why (even with internal provision) investment levels are decreasing in $\gamma$.

Finally, to understand why investment incentives improve compared to the case in which the incumbent can not enable a spin-off, it is useful to distinguish between the situation in which a start-up would form without internal provision and that in which it would not. In the former, allowing for internal provision shifts part of the profits generated by the spin-off from the external provider of complementary assets to the incumbent; hence, the incentives to invest increase. In the latter, the results follow directly from the observation that the marginal return on investment is larger if a spin-off is formed. 


\section{Discussion and Concluding Remarks}

In this paper, we study the effects of the availability of complementary assets on the process of start-up formation and on the R\&D investments of parent firms. Start up formation requires complementary assets that need to be searched for in the market. We show that the existence of search frictions in the complementary assets 'market' may exert a positive effect on incumbents' innovative investments leading to an increase in total industry profits. This implies that, contrary to the common view, frictions may improve efficiency, where with a slight abuse of notation (given that we focus on the supply side) we refer to maximal total industry profits as an efficiency benchmark.

The main result of this paper is to fully characterize under which conditions search frictions exert positive effects. We show that different implications arise depending crucially on the effect that an increase in knowledge stemming from R\&D investment has on the losses of the incumbent and on the profits of the employee upon start-up formation. We find that for industries where substantial R\&D knowledge is needed for profitable start-up formation, the creation of a start up also requires easy access to complementary assets. Conversely, when a low level of R\&D knowledge suffices for the creation of a successful start-up, start-up formation occurs even if complementary assets are difficult to obtain.

Two different types of inefficiencies may arise in our framework. If limited appropriability of the R\&D investment returns by the incumbent leads to under-investment, we face ex-ante inefficiencies occurring before the decision about start-up formation is made. If no start-up is created although total industry profits could be increased by founding one, ex-post inefficiencies occur. Interpreting our results with respect to these efficiency considerations, more refined implications arise. Standard arguments establish that the possibility of start-up formation always lead to ex-ante inefficiencies. We argue that there are situations in which the presence of search frictions may reduce the amount of under-investment. When complementary assets are scarce (so that search frictions are large), a gradual increase in their availability has strictly negative effects on efficiency, since ex-ante inefficiencies increase and ex-post inefficiencies persist (because start-up formation does not occur). Ex-post inefficiencies disappear when potential start-up founders have easy access to complementary assets $(\gamma>\bar{\gamma})$, so that start-up formation occurs. However, for industries characterized by decreasing knowledge effects, such an easy access to complementary assets induces larger ex-ante under-investment in $\mathrm{R} \& \mathrm{D}$ than in all cases in which the employee remains employed at the firm. Therefore, for these industries, if search frictions are sufficiently strong to prevent the formation of a start-up $(\gamma<\bar{\gamma})$, the extent of ex-ante under-investment by the incumbent is reduced. This does not hold true for industries characterized by increasing knowledge effects, since in this case an increase of $\gamma$ across the $\bar{\gamma}$ threshold leads both to the elimination of ex-post inefficiencies and to a reduction of the ex-ante under-investment.

Based on the results summarized above, a number of interesting conclusions can be drawn for specific industries. In order to do so, it is important to note that the analysis in the paper focuses on the interaction between a single firm and its key R\&D employee. From an industry perspective, however, the heterogeneity among firms and employees has to be taken into account. In particular, it should be noted that the threshold value 
of search frictions that leads to start-up formation $(\bar{\gamma})$ differs across firms, which means that some profitable start-ups might be prevented by these frictions although start-up formation is observed in the industry. Since industries differ substantially in the nature of the complementary assets that are needed to create a start-up, different implications of our model arise for different industries.

As already noted in the Introduction, in the biotechnology industry highly specific complementary assets are required for the commercialization of innovations, which to a large extent have to be obtained through alliances with incumbent firms. As it has also been noted by practitioners in the industry ${ }^{12}$, this implies that for the biotechnology industry access to the needed complementary assets is relatively difficult and a major obstacle for start-up formation. In terms of our analysis, this corresponds to an industry with a low value of $\gamma$. Our analysis suggests that in this case a small increase in the accessibility of complementary assets has negative implications for existing firms' incentives to invest in $\mathrm{R} \& \mathrm{D}$, without eliminating the problem that profitable start-ups may not be founded. Hence, a substantial increase in the availability of complementary assets is needed for start-ups increasing total industry profits to be actually founded. This implies that policy measures and private initiatives facilitating the access of potential founders to the required resources need to be large in order to be effective. Specific examples in this respect might be large scale programs aimed at easing access to clinical trials and regulatory capabilities, either by creating open facilities or by providing the necessary financial means. At the same time, however, our analysis also calls for caution with such large programs, since the induced reduction in R\&D investments by incumbents might outweigh the positive effects of additional start-ups in terms of generated total industry profits (see Figure 4).

Different conclusions are reached if one looks at the computer industry, where the needed complementary assets are known to be generic (see Rothaermel and Hill (2005) for a discussion) and therefore readily available. Interpreting this as an indication that for many potential start-ups in the industry the availability of complementary assets are above the threshold $\bar{\gamma}$, our results imply that no negative effects on R\&D incentives of incumbents should be expected if the availability of complementary assets in the market is further improved.

More generally, our results lead to a number of testable implications that can be taken to the data. The strategic effect linking the incumbent's innovative efforts to the key employee's outside option lies at the hearth of the paper, predicting a negative relationship between the incumbent's incentives to invest in $\mathrm{R} \& \mathrm{D}$ and the availability of complementary assets ${ }^{13}$. Colombo et $\mathrm{Al}$. (2013) investigate the empirical relevance

\footnotetext{
${ }^{12}$ For example J. Dixon, a former scientist and founder of several biotechnology companies states (see http://blogs.nature.com/tradesecrets/2011/08/09/strategic-issues-facing-biotech-start-ups) "The hard reality is that drug development is an expensive process and access to capital is a massive constraint. The high costs are largely driven by the high quality standards inherent in clinical trials and manufacturing in order to pass stringent regulatory hurdles that stand between our innovations and commercializing a product. And for the most part, we need access to assets that are outside of our companies such as clinical and regulatory capabilities, manufacturing, sales and marketing infrastructure and the like. Financial constraint often impairs our ability to build these assets internally, some of which may be needed to deal with regulatory burden."

${ }^{13}$ This negative relationship should not be observed if $\gamma$ is larger than $\bar{\gamma}$, in which case complementary assets are so abundant that the R\&D effort of the incumbent is no longer affected by them.
} 
of the above strategic effect using a panel of Italian firms, finding strong support for the existence of such a negative relationship in the data. Further testable implications, to be addressed in future research, arise when focusing on the degree of availability of complementary assets. First, in industries where the availability of complementary assets is scarce, we expect a negative effect of the increase in complementary assets on investments in R\&D and on incumbents' profits ${ }^{14}$. Conversely, in industries with easy access to complementary assets, an increase in the availability of complementary assets should have no effects both on investments in R\&D and on incumbents' profits. Second, our theoretical model predicts that the amount of knowledge needed to observe the creation of profitable start-ups in industries characterized by increasing knowledge effects is larger than the one needed in industries with decreasing knowledge effects. An empirical strategy to classify the two types of industries according to the effects of $\mathrm{R} \& \mathrm{D}$ knowledge is therefore to estimate the knowledge base of newly founded startups. We can then use such an empirical proxy as an indicator of the presence of increasing or decreasing knowledge effects in different industries and bring to the data a second testable implication of our model. According to our theoretical analysis, for intermediate levels of complementary assets availability (i.e., those levels for which start-up formation is observed, but missing access to complementary assets prevents formation of some start-ups that would otherwise be created), programs aimed at easing the access to complementary assets should have a negative impact on $R \& D$ investments in the industries characterized by increasing knowledge effects, while they should bear no implications for R\&D industries with decreasing knowledge effects.

Finally, on theoretical grounds, our setup can be extended in several directions. In particular, a main drawback of our static model structure is that the dynamic effects of start-up formation on the evolution of competition and industry structure, as well as future knowledge flows, can not be captured. Developing and analyzing models combining dynamic features with the strategic effects considered here is a challenging area for future research. A first step in this direction has been made by Colombo et Al. (2012), in which the strategic effects at play in the start-up formation process have been embedded in an industry evolution model.

\section{References}

Acs, J., And L. Plummer (2005): "Penetrating the "knowledge filter" in regional economies," Annals of Regional Science, 39(3), 439-456.

Aghion, P., And J. Tirole (1994): "The Management of Innovation," Quarterly Journal of Economics, 113, 1185-1209.

Anand, B., and A. Galetovic (2000): "Weak Property Rights and Holdup in R\&D," Journal of Economics and Management Strategy, 9(4), 615-642.

(2004): "Strategies that Work when Property Rights Don't," in Intellectual Property and Entrepreneurship, ed. by G. Libecap. Greenwich, Conn.: JAI Press.

\footnotetext{
${ }^{14}$ It should be noted that we restrict attention to industries in which the generation of a start-up is profitable (i.e., $\Delta \pi_{E}>0$ ). For industries in which the absence of start-ups is due to the fact that they are not profitable, an increase in complementary assets should have no effects.
} 
Anton, J., And D. Yao (1994): "Expropriation and Inventions: Appropriable Rents in the Absence of Property Rights," American Economic Review, 84(1), 190-209.

(1995): "Start-ups, Spin-offs, and Internal Projects," Journal of Law, Economics \& Organization, 11(2), 362-378.

(2002): "The Sale of Ideas: Strategic Disclosure, Property Rights, and Contracting," Review of Economic Studies, 69(3), 513-531.

Arrow, K. (1962): "Economic Welfare and the Allocation of Resources for Invention," in The Rate and Direction of Inventive Activity, ed. by R. Nelson. New York: Princeton University Press.

Baccara, M., and R. RAzin (2012): "Innovation and Corporate Conservatism," Mimeo. London School of Economics.

Becker, G. (1962): "Investment in Human Capital: A Theoretical Analysis," Journal of Political Economy, 70(5), 9-49.

Colombo, L., H. Dawid, and K. Kabus (2012): "When Do Thick Venture Capital Markets Foster Innovation? An Evolutionary Analysis," Journal of Evolutionary Economics, 22, 79-108.

Colombo, L., H. Dawid, M. Piva, and M. Vivarelli (2013): "Does Easy StartUp Formation Hamper Incumbents R\&D Investment? A Theoretical and Empirical Analysis," Bielefeld Working Papers in Economics and Management No. 08-2013.

Cowan, R., P. David, And D. Foray (2000): "The explicit economics of codification and tacitness," Industrial and Corporate Change, 9, 211-253.

Curran, D., C. van Egeraat, and C. O'Gorman (2011): "New Entrants and Inherited Competence: The Evolution of the Irish Biotech Sector," NIRSA Working Paper No. 66.

Dahl, M., C. Ostergaard, and B. Dalum (2010): "Emergence of Regional Cluster - The Role of Spinoffs in The Early Growth Process," in Handbook of Evolutionary Economic Geography, ed. by R. Martin, and R. Boschma, pp. 205-221. Edward Elgar.

Fallick, B., C. Fleischman, and J. Rebitzer (2006): "Job-Hopping in Silicon Valley: Some Evidence Concerning the Microfoundations of a High-Technology Cluster," Review of Economics and Statistics, 88, 472-481.

Franco, A., And D. Filson (2006): "Spin-Outs: Knowledge Diffusion through Employee Mobility," The RAND Journal of Economics, 37(4), 841-860.

Gersbach, H., And A. Schmutzler (2003a): "Endogenous spillovers and incentives to innovate," Economic Theory, 21, 59-79.

(2003b): "Endogenous technological spillovers: causes and consequences," Journal of Economics and Management Strategy, 12, 179-205. 
KLEPPER, S. (2010): "The origin and growth of industry clusters: The making of Silicon Valley and Detroit," Journal of Urban Economics, 67(1), 15-32.

Klepper, S., And S. Sleeper (2005): "Entry by Spinoffs," Management Science, 51(8), 1291-1306.

Park, H., and H. Steensma (2012): "When Does Corporate Venture Capital Add Value for New Ventures?," Strategic Management Journal, 33, 1-22.

Polanyi, M. (1966): The Tacit Dimension. London: Routledge and Kegan Paul.

Rothaermel, F., and D. Deeds (2004): "Exploration and Exploitation Alliances in Biotechnology: a System of New Product Development," Strategic Management Journal, 25, 201-221.

Rothaermel, F., and C. Hill (2005): "Technological Discontinuities and Complementary Assets: a Longtudinal Study of Industry and Firm Performance," Organization Science, 16, 50-70.

Saxenian, A. (1994): Regional Advantage: Culture and Competition in Silicon Valley and Route 128. Cambridge: Harvard University Press.

Spulber, D. (2012): "Tacit Knowledge with Innovative Entrepreneurship," International Journal of Industrial Organization, 30, 641-653.

Symeonidis, G. (2003): "Comparing Cournot and Betrand Equilibria in a Differentiated Duopoly with Product R\& D," International Journal of Industrial Organization, $21,39-55$.

Teece, D. (1986): "Profiting from Technological Innovation: Implications for Integration, Collaboration, Licensing and Public Policy," Research Policy, 15, 285-305.

Zucker, L., M. Darby, and M. Brewer (1998): "Intellectual Human Capital and the Birth of U.S. Biotechnology Enterprises," American Economic Review, 88, 290306.

\section{Appendix A}

In this Appendix, we use a quality-augmented duopoly model with linear demand (see Symeonidis (2003)) to qualitatively exemplify the effects characterized in our general analysis and gain a better understanding of the differences between increasing and decreasing knowledge effects.

We consider a market in which, without start-ups, the incumbent acts as a monopolist. Consumers are characterized by quality augmented Dixit-Stiglitz-type utility functions. The corresponding inverse market demand is given by

$$
p_{F}^{m}=1-2 \frac{q_{F}^{m}}{u_{F}^{m 2}},
$$


where $u_{F}^{m}$ denotes the quality of the good offered. Marginal costs are constant and denoted by $0<c_{F}<1$. The optimal behavior of the monopolist yields the profit

$$
\tilde{\pi}_{F}^{m}=\frac{\left(1-c_{F}\right)^{2} u^{2}}{8} .
$$

We assume that the relationship between product quality and the knowledge $K$ is given by

$$
u_{F}^{m}=K^{\mu}, \mu>0,
$$

and the investment needed to generate $K$ by

$$
I(K)=\iota K^{\nu}, \nu>1, \iota>0 .
$$

Accordingly, the profit function can be written as

$$
\pi_{F}^{m}(K)=\tilde{\pi}_{F}^{m}=\frac{\left(1-c_{F}\right)^{2} K^{2 \mu}}{8} .
$$

In case a start-up is formed, the quality of the product the incumbent's can offer on the market is

$$
u_{F}^{s}=(\delta K)^{\mu},
$$

whereas the quality of the start-up's product is

$$
u_{E}^{s}=K^{\mu} .
$$

Furthermore, the two products are horizontally differentiated. Denoting by $\left(p_{F}^{s}, p_{E}^{s}\right)$ and $\left(q_{F}^{s}, q_{E}^{s}\right)$ the prices and quantities of the incumbent and of the start-up in case a start-up is crated, the inverse demand system can be written as

$$
\begin{aligned}
& p_{F}^{s}=1-2 \frac{q_{F}^{s}}{u_{F}^{s} 2}-\frac{\sigma q_{E}^{s}}{u_{F}^{s} u_{E}^{s}} \\
& p_{E}^{s}=1-2 \frac{q_{E}^{s}}{u_{E}^{s}{ }^{2}}-\frac{\sigma q_{F}^{s}}{u_{F}^{s} u_{E}^{s}} .
\end{aligned}
$$

The parameter $\sigma \in[0,2]$ determines the degree of horizontal differentiation, where lower values of $\sigma$ correspond to a higher degree of differentiation. The constant marginal production costs of the start-up are denoted by $c_{E}$ and we assume that, due to the presence of learning curve effects, the start-up's marginal production costs are larger or equal than those of the incumbent; i.e., $c_{E} \geq c_{F}$. Assuming that the two firms engage in quantity competition, standard calculations yield the following profits in the Cournot equilibrium:

$$
\begin{aligned}
& \tilde{\pi}_{F}^{s}=2\left(\frac{4\left(1-c_{F}\right) u_{F}^{s}-\sigma\left(1-c_{E}\right) u_{E}^{s}}{(4-\sigma)(4+\sigma)}\right)^{2} \\
& \tilde{\pi}_{E}^{s}=2\left(\frac{4\left(1-c_{E}\right) u_{E}^{s}-\sigma\left(1-c_{F}\right) u_{F}^{s}}{(4-\sigma)(4+\sigma)}\right)^{2} .
\end{aligned}
$$


Inserting (5) and (6) into these expressions, we obtain

$$
\begin{aligned}
& \pi_{F}^{s}=2 K^{2 \mu} \frac{\left(4\left(1-c_{F}\right) \delta^{\mu}-\sigma\left(1-c_{E}\right)\right)^{2}}{(4-\sigma)^{2}(4+\sigma)^{2}} \\
& \pi_{E}^{s}=2 K^{2 \mu} \frac{\left(4\left(1-c_{E}\right)-\sigma\left(1-c_{F}\right) \delta^{\mu}\right)^{2}}{(4-\sigma)^{2}(4+\sigma)^{2}} .
\end{aligned}
$$

From (4) and (7), we get

$$
\Delta \pi_{F}=2 K^{2 \mu}\left(\frac{\left(1-c_{F}\right)^{2}}{16}-\frac{\left(4\left(1-c_{F}\right) \delta^{\mu}-\sigma\left(1-c_{E}\right)\right)^{2}}{(4-\sigma)^{2}(4+\sigma)^{2}}\right) .
$$

For the sake of simplicity, we assume also that the cost of providing the complementary assets required to found a start-up is given by the following polynomial in $K$,

$$
C(K)=a K^{\lambda},
$$

which gives

$$
\Delta \pi_{E}=2 K^{2 \mu} \frac{\left(4\left(1-c_{E}\right)-\sigma\left(1-c_{F}\right) \delta^{\mu}\right)^{2}}{(4-\sigma)^{2}(4+\sigma)^{2}}-a K^{\lambda} .
$$

It is easy to check that these functional forms satisfy all assumptions made in our general analysis.

The elasticity of $\Delta \pi_{F}$ is constant and given by

$$
\epsilon_{F}(K)=2 \mu,
$$

whereas the elasticity of $\Delta \pi_{E}$ is

$$
\begin{aligned}
\epsilon_{E}(K) & =\frac{4 \mu K^{2 \mu}\left(4\left(1-c_{E}\right)-\sigma \delta^{\mu}\left(1-c_{F}\right)\right)^{2}-(4-\sigma)^{2}(4+\sigma)^{2} \lambda a K^{\lambda}}{2 K^{2 \mu}\left(4\left(1-c_{E}\right)-\sigma \delta^{\mu}\left(1-c_{F}\right)\right)^{2}-(4-\sigma)^{2}(4+\sigma)^{2} a K^{\lambda}} \\
& =2 \mu \frac{2 K^{2 \mu}\left(4\left(1-c_{E}\right)-\sigma \delta^{\mu}\left(1-c_{F}\right)\right)^{2}-\frac{\lambda}{2 \mu}(4-\sigma)^{2}(4+\sigma)^{2} a K^{\lambda}}{2 K^{2 \mu}\left(4\left(1-c_{E}\right)-\sigma \delta^{\mu}\left(1-c_{F}\right)\right)^{2}-(4-\sigma)^{2}(4+\sigma)^{2} a K^{\lambda}} .
\end{aligned}
$$

It is then easy to conclude that $\epsilon_{F}(K) \leq \epsilon_{E}(K)$ if and only if

$$
\mu \geq \frac{\lambda}{2}
$$

It should be noted that the Condition (12) for an increasing knowledge effect is independent from the values of all demand and cost parameters, as it depends only on the elasticity of the product quality and of the cost of providing the complementary assets with respect to the stock of knowledge $K$. If the elasticity of product quality with respect to knowledge is large relative to that of the cost of the complementary assets, market profits (monopoly and duopoly profits) are growing with $K$ at a higher rate than the costs of the required complementary assets. Therefore, the marginal positive effects of knowledge investment on net industry profits are smaller for low than for high investment levels, and we have an increasing effect of knowledge. For small values of $\mu$ 
these effects are reversed, and we have a decreasing knowledge effect.

Figures 2 to 4 in the main text are based on the linear example described above with parameter values

$$
a=0.005, \lambda=1.5, \iota=0.05, \nu=3, \sigma=0.7, c_{F}=0.2, c_{E}=0.25, \delta=0.9, \xi=0.5 .
$$

The condition for an increasing knowledge effect is $\mu \geq 0.75$. In the figures, we set $\mu=1$ to illustrate cases with an increasing knowledge effect, and $\mu=0.5$ for the cases with a decreasing knowledge effect.

\section{Appendix B}

\section{Lemma 7}

(i) If $\Delta \pi_{E}(K)-\Delta \pi_{F}(K)$ is everywhere elastic, then $\epsilon_{E}(K)>\epsilon_{F}(K)$ holds for all $K$.

(ii) If $\epsilon_{E}(K)<\epsilon_{F}(K)$ for all $K$, then $\Delta \pi_{E}(K)-\Delta \pi_{F}(K)$ is everywhere inelastic.

\section{Proof}

We first consider Claim (ii). To prove it, we need to show that

$$
\frac{\left(\Delta \pi_{E}^{\prime}(K)-\Delta \pi_{F}^{\prime}(K)\right) K}{\Delta \pi_{E}(K)-\Delta \pi_{F}(K)}<1
$$

for all $K$. Inequality (13) is equivalent to

$$
\begin{array}{rlrl}
K \Delta \pi_{E}^{\prime}(K)-K \Delta \pi_{F}^{\prime}(K) & <\Delta \pi_{E}(K)-\Delta \pi_{F}(K) \\
\Leftrightarrow & \epsilon_{E}(K)-\frac{\Delta \pi_{F}(K)}{\Delta \pi_{E}(K)} \epsilon_{F}(K) & <1-\frac{\Delta \pi_{F}(K)}{\Delta \pi_{E}(K)} \\
\Leftrightarrow & & \frac{\Delta \pi_{F}(K)}{\Delta \pi_{E}(K)}\left(1-\epsilon_{F}(K)\right) & <1-\epsilon_{E}(K) .
\end{array}
$$

Since $\epsilon_{F}(K)>\epsilon_{E}(K)$ and $\frac{\Delta \pi_{F}(K)}{\Delta \pi_{E}(K)}<1$ by Assumption 2, the last inequality holds for all $K$, and therefore (13) holds.

In order to prove Claim (i), assume that there is a $\hat{K}$ such that $\epsilon_{E}(\hat{K})<\epsilon_{F}(\hat{K})$. Then, from the proof of Claim (ii) it must be that

$$
\frac{\left.\left(\Delta \pi_{E}^{\prime}(\hat{K})-\Delta \pi_{F}^{\prime}(\hat{K})\right) \hat{K}\right)^{\prime}}{\Delta \pi_{E}(\hat{K})-\Delta \pi_{F}(\hat{K})}<1 .
$$

This contradicts the statement that $\Delta \pi_{E}(K)-\Delta \pi_{F}(K)$ is everywhere elastic.

\section{Proof of Lemma 1}

Note first that in case of agreement the total profit of the two bargaining parties is given by $\pi_{F}^{m}(K)-I(K)$. Furthermore, the threat points of the two parties are given 
by their payoffs if the game moves to stage three, which are $P_{F}^{s}$ for the incumbent and $P_{E}^{s}$ for the employee. Therefore, the bargaining results in disagreement if and only if

$$
\pi_{F}^{m}-I(K)<P_{F}^{s}+P_{E}^{s}=\pi_{F}^{s}(K)-I(K)+\gamma \Delta \pi_{E} .
$$

This inequality is equivalent to $G(K ; \gamma)>0$, which proves part (i) of the Lemma. Part (ii) follows directly from the generalized Nash bargaining solution, which allocates

$$
P_{F}=P_{F}^{s}+\xi\left(\pi_{F}^{m}(K)-I(K)-P_{F}^{s}-P_{E}^{s}\right)
$$

to the incumbent firm in case of agreement. In case of disagreement, the payoff of the firm is given by its threat point $P_{F}^{s}$. Part (iii) of the Lemma can be proven in the same way.

\section{Proof of Proposition 2}

(i) $\quad K^{*}(\gamma)=\bar{K}_{m}$ if and only if $P_{F}^{m}\left(\bar{K}_{m} ; \gamma\right)-P_{F}^{s}\left(\bar{K}_{s}\right) \geq 0$. Notice that, for $\gamma=0$, we have

$$
\begin{aligned}
P_{F}^{m}\left(\bar{K}_{m} ; 0\right)-P_{F}^{s}\left(\bar{K}_{s}\right) & \geq P_{F}^{m}\left(\bar{K}_{s} ; 0\right)-P_{F}^{s}\left(\bar{K}_{s}\right) \\
& =\xi \Delta \pi_{F}\left(\bar{K}_{s}\right) \\
& >0
\end{aligned}
$$

where the last inequality follows from Assumption 2. Furthermore, using the envelope theorem, we get

$$
\begin{aligned}
\frac{d\left(P_{F}^{m}\left(\bar{K}_{m} ; \gamma\right)-P_{F}^{s}\left(\bar{K}_{s}\right)\right)}{d \gamma} & =\frac{\partial\left(P_{F}^{m}\left(\bar{K}_{m} ; \gamma\right)-P_{F}^{s}\left(\bar{K}_{s}\right)\right)}{\partial \gamma} \\
& <\frac{\partial P_{F}^{m}\left(\bar{K}_{m}\right)}{\partial \gamma}<0 .
\end{aligned}
$$

If $P_{F}^{m}\left(\bar{K}_{m} ; 1\right)-P_{F}^{s}\left(\bar{K}_{s}\right)>0$, we set $\bar{\gamma}=1$ and $K^{*}(\gamma)=\bar{K}_{E, m}$ for all $\gamma \in(0,1]$. Otherwise, there exists a unique $\bar{\gamma} \in(0,1]$ such that $P_{F}^{m}\left(\bar{K}_{m} ; \bar{\gamma}\right)-P_{F}^{s}\left(\bar{K}_{s}\right)=0$, and the first claim of the proposition follows.

(ii) Given that $\bar{K}_{s}$ is independent from $\gamma$, the claim follows directly from $\frac{\partial \bar{K}_{m}}{\partial \gamma}=$ $-\frac{\partial^{2} P_{F}^{m}}{\partial \gamma \partial K} / \frac{\partial^{2} P_{F}^{m}}{\partial K^{2}}$, the concavity of $P_{F}^{m}$ and part (ii) of Lemma 1 .

(iii) Using the definition of $\bar{K}_{m}$ and $K^{e f f}$ and Assumption 2, from

$$
\begin{aligned}
& \frac{\partial\left(P_{F}^{m}(K ; \gamma)-\left(\pi_{F}^{s}(K)+\Delta \pi_{E}^{s}(K)-I(K)\right)\right.}{\partial K} \\
& \quad=\xi \Delta \pi_{F}^{\prime}(K)-(\xi \gamma+1) \Delta \pi_{E}^{\prime}(K) \\
& \quad<0
\end{aligned}
$$

it follows that $\bar{K}_{m}<K^{e f f}$. Analogously, we obtain $\bar{K}_{s}<K^{e f f}$. These two inequalities combined lead to $K^{*}(\gamma)<K^{e f f}$, which proves the claim. 


\section{Proof of Proposition 3}

To prove part (i) we show that $\bar{K}_{m}>\bar{K}_{s}$ for $\gamma=0$ and $\bar{K}_{E, m}<\bar{K}_{s}$ for $\gamma=1$. If $\gamma=0$ then $\frac{d\left(P_{F}^{m}-P_{F}^{s}\right)}{d K}=-\xi G^{\prime}(K ; 0)>0$ by Assumption 2. Hence, $\frac{d\left(P_{F}^{m}\left(\bar{K}_{s} ; 0\right)\right)}{d K}>0$, which implies $\bar{K}_{m}>\bar{K}_{s}$. If $\gamma=1$ then $\frac{d\left(P_{F}^{m}-P_{F}^{s}\right)}{d K}=-\xi G^{\prime}(K ; 1)<0$ again by Assumption 2. Hence, $\frac{d\left(P_{F}^{m}\left(\bar{K}_{s} ; 1\right)\right)}{d K}<0$, which implies $\bar{K}_{E, m}<\bar{K}_{s}$. Claim (i) follows from the monotonicity of $\bar{K}_{m}-\bar{K}_{s}$ with respect to $\gamma$.

To prove parts (ii) and (iii) we first establish that $G^{\prime}\left(\bar{K}_{s} ; \hat{\gamma}\right)=G^{\prime}\left(\bar{K}_{m}(\hat{\gamma}) ; \hat{\gamma}\right)=0$. For $\gamma=\hat{\gamma}$, we have that $\bar{K}_{m}=\bar{K}_{s}$. Therefore, $P_{F}^{m \prime}\left(\bar{K}_{s} ; \hat{\gamma}\right)=P_{F}^{s^{\prime}}\left(\bar{K}_{s} ; \hat{\gamma}\right)=0$, which implies

$$
P_{F}^{m \prime}\left(\bar{K}_{s} ; \hat{\gamma}\right)-P_{F}^{s \prime}\left(\bar{K}_{s} ; \hat{\gamma}\right)=-\xi G^{\prime}\left(\bar{K}_{s} ; \hat{\gamma}\right)=0 .
$$

Accordingly, it must be that $G^{\prime}\left(\bar{K}_{s} ; \hat{\gamma}\right)=0$ and therefore also $G^{\prime}\left(\bar{K}_{m}(\hat{\gamma}) ; \hat{\gamma}\right)=0$.

Consider now the case in which knowledge has an increasing effect. Taking into account Proposition 2, all we have to show is that $\bar{\gamma}>\hat{\gamma}$. Note first that, under the assumption of an increasing knowledge effect, we have

$$
\frac{\Delta \pi_{F}^{\prime}(K)}{\Delta \pi_{E}^{\prime}(K)}<\frac{\Delta \pi_{F}(K)}{\Delta \pi_{E}(K)}
$$

for all $K>0$. Furthermore, it has been shown above that $G^{\prime}\left(\bar{K}_{s} ; \hat{\gamma}\right)=G^{\prime}\left(\bar{K}_{m}(\hat{\gamma}) ; \hat{\gamma}\right)=$ 0 , which implies that

$$
\hat{\gamma}=\frac{\Delta \pi_{F}^{\prime}\left(\bar{K}_{s}\right)}{\Delta \pi_{E}^{\prime}\left(\bar{K}_{s}\right)}
$$

by definition of $G$.

Hence,

$$
\begin{aligned}
& P_{F}^{m}\left(\bar{K}_{m}(\hat{\gamma}) ; \hat{\gamma}\right)-P_{F}^{s}\left(\bar{K}_{s}\right) \\
& \quad=P_{F}^{m}\left(\bar{K}_{s} ; \hat{\gamma}\right)-P_{F}^{s}\left(\bar{K}_{s}\right) \\
& \quad=\xi\left(\Delta \pi_{F}\left(\bar{K}_{s}\right)-\hat{\gamma} \Delta \pi_{E}\left(\bar{K}_{s}\right)\right) \\
& \quad=\xi\left(\Delta \pi_{F}\left(\bar{K}_{s}\right)-\frac{\Delta \pi_{F}^{\prime}\left(\bar{K}_{s}\right)}{\Delta \pi_{E}^{\prime}\left(\bar{K}_{s}\right)} \Delta \pi_{E}\left(\bar{K}_{s}\right)\right) \\
& \quad>0,
\end{aligned}
$$

where the last inequality follows from (14). Accordingly, for $\gamma=\hat{\gamma}$ no start-up is formed, and it must be $\bar{\gamma}>\hat{\gamma}$. Since $\bar{K}_{m}(\hat{\gamma})=\bar{K}_{s}$ and $\bar{K}_{m}$ is decreasing with respect to $\gamma$, the optimal investment $K^{*}(\gamma)$ exhibits an upward jump at $\gamma=\bar{\gamma}$.

The proof that $\bar{\gamma}<\hat{\gamma}$ when knowledge has a decreasing effect proceeds along the same lines as above, where it has to be taken into account that if knowledge has a decreasing effect then

$$
\Delta \pi_{F}\left(\bar{K}_{s}\right)-\frac{\Delta \pi_{F}^{\prime}\left(\bar{K}_{s}\right)}{\Delta \pi_{E}^{\prime}\left(\bar{K}_{s}\right)} \Delta \pi_{E}\left(\bar{K}_{s}\right)<0 .
$$


The claims concerning $\bar{K}_{m}$ and the downward jump of $K^{*}(\gamma)$ follow directly.

\section{Proof of Proposition 4}

We first state and prove the following Lemma.

\section{Lemma 8}

(i) $P_{F}^{*}(\gamma)$ is single-valued and continuous on $(0,1]$;

(ii) $P_{E}^{*}(\gamma)$ is single-valued and continuous for $\gamma \neq \bar{\gamma}$.

\section{Proof}

(i) For $\gamma \neq \bar{\gamma}$ there is a unique optimal investment level for the firm, and therefore $P_{F}^{*}(\gamma)$ is single-valued. For $\gamma=\bar{\gamma}$, there are two optimal investment levels, one with and one without start-up formation, but the profit of the firm is the same in both situations, due to the definition of $\bar{\gamma}$. Hence, $P_{F}^{*}(\gamma)$ is single-valued and continuous.

(ii) The fact that $P_{E}^{*}(\gamma)$ is single-valued follows immediately from the uniqueness of the optimal investment level for $\gamma \neq \bar{\gamma}$. Continuity follows directly from the continuity of $P_{E}^{s}$ and $P_{E}^{m}$.

We can now turn to the proof of the proposition.

(i) Note that

$$
P_{F}^{*}(\gamma)= \begin{cases}P_{F}^{m}\left(\bar{K}_{m}(\gamma) ; \gamma\right) & \text { for } \gamma<\bar{\gamma} \\ P_{F}^{s}\left(\bar{K}_{s}\right) & \text { otherwise. }\end{cases}
$$

Using the envelope theorem, for $\gamma<\bar{\gamma}$, we obtain that

$$
\frac{\partial P_{F}^{*}(\gamma)}{\partial \gamma}=\frac{\partial P_{F}^{m}\left(\bar{K}_{m}(\gamma) ; \gamma\right)}{\partial \gamma}=-\xi \Delta \pi_{E}\left(\bar{K}_{m}(\gamma)\right)<0
$$

For $\gamma \geq \bar{\gamma}$, the claim follows from the independence of $P_{F}^{s}$ from $\gamma$.

(ii) The claim follows directly from Lemma 1 , as for $\gamma>\bar{\gamma}$ a start-up is formed, the firm's investment level is constant in $\gamma$ and the corresponding employee's payoff is given by $P_{E}^{s}$.

(iii) If $\gamma<\bar{\gamma}$, the employee's payoff is given by

$$
\begin{aligned}
P_{E}^{*}(\gamma) & =P_{E}^{m} \\
& =\gamma \Delta \pi_{E}\left(\bar{K}_{m}\right)-(1-\xi) G\left(\bar{K}_{m} ; \gamma\right) .
\end{aligned}
$$

Taking this into account, we have that

$$
\begin{aligned}
\lim _{\gamma \rightarrow \bar{\gamma}-} P_{E}^{*}(\gamma) & =\bar{\gamma} \Delta \pi_{E}\left(\bar{K}_{m}(\bar{\gamma})\right)-(1-\xi) G\left(\bar{K}_{m}(\bar{\gamma}) ; \bar{\gamma}\right) \\
\lim _{\gamma \rightarrow \bar{\gamma}+} P_{E}^{*}(\gamma) & =\bar{\gamma} \Delta \pi_{E}\left(\bar{K}_{s}\right) .
\end{aligned}
$$


From Proposition 3, we know that if knowledge has a decreasing effect then $\bar{K}_{m}(\bar{\gamma})>$ $\bar{K}_{s}$. Furthermore, it is

$$
\begin{aligned}
G & \left(\bar{K}_{m}(\bar{\gamma}) ; \bar{\gamma}\right) \\
& =\frac{-1}{\xi}\left(P_{F}^{m}\left(\bar{K}_{m}(\bar{\gamma}) ; \bar{\gamma}\right)-P_{F}^{s}\left(\bar{K}_{m}(\bar{\gamma})\right)\right. \\
& \leq \frac{-1}{\xi}\left(P_{F}^{m}\left(\bar{K}_{m}(\bar{\gamma}) ; \bar{\gamma}\right)-P_{F}^{s}\left(\bar{K}_{s}\right)\right. \\
& =0
\end{aligned}
$$

where the inequality follows from the definition of $\bar{K}_{s}$ and the last equality from the definition of $\bar{\gamma}$. Taking $G\left(\bar{K}_{m}(\bar{\gamma}) ; \bar{\gamma}\right) \leq 0$ into account, the strict monotonicity of $\Delta \pi_{E}$ with respect to $K$ establishes that

$$
\lim _{\gamma \rightarrow \bar{\gamma}-} P_{E}^{*}(\gamma)>\lim _{\gamma \rightarrow \bar{\gamma}+} P_{E}^{*}(\gamma)
$$

which proves the claim.

\section{Proof of Proposition 5}

(i) The joint surplus in the bargaining between the firm and the employee is given by $\pi_{F}^{m}(K)-\pi_{F}^{m}(\delta K)>0$, and therefore the bargaining never results in disagreement. (ii) In the presence of a non-compete clause, the payoff of the firm is given by

$$
P_{F}^{n c}(K)=\xi \pi_{F}^{m}(K)+(1-\xi) \pi_{F}^{m}(\delta K)-I(K)
$$

and $K^{n c *}$ is the value of $K$ maximizing this expression. Taking into account parts (i) and (ii) of Proposition 2, it is sufficient to show that $K^{n c}>K^{*}(0)=\bar{K}_{F}^{m}(0)$. The first order condition satisfied by $\bar{K}_{F}^{m}(0)$ reads

$$
P_{F}^{m}\left(\bar{K}_{F}^{m}(0) ; 0\right)^{\prime}=\xi \pi_{F}^{m}\left(\bar{K}_{F}^{m}(0)\right)^{\prime}+(1-\xi) \pi_{F}^{s}\left(\bar{K}_{F}^{m}(0)\right)^{\prime}-I^{\prime}\left(\bar{K}_{F}^{m}(0)\right)=0 .
$$

Due to the assumption that $\delta \pi_{F}^{m}(\delta K)^{\prime}>\pi_{F}^{s}(K)^{\prime}$, we obtain

$$
P_{F}^{n c}\left(\bar{K}_{F}^{m}(0)\right)^{\prime}=\xi \pi_{F}^{m}\left(\bar{K}_{F}^{m}(0)\right)^{\prime}+(1-\xi) \delta \pi_{F}^{m}\left(\delta \bar{K}_{F}^{m}(0)\right)^{\prime}-I\left(\bar{K}_{F}^{m}(0)\right)>0,
$$

and therefore $K^{n c *}>\bar{K}_{F}^{m}(0)$.

(iii) First, note that, since $\delta \pi_{F}^{m}(\delta K)^{\prime}>\pi_{F}^{s}(K)^{\prime}$ by assumption, we can write

$$
\pi_{F}^{m}(\delta K)-\pi_{F}^{s}(K)=\int_{0}^{K}\left(\delta \pi_{F}^{m}(\delta x)^{\prime}-\pi_{F}^{s}(x)^{\prime}\right) d x>0,
$$

for all $K>0$. Considering the payoff of the incumbent firm, using Lemma 1, we have 
that

$$
\begin{aligned}
P_{F}^{*}(\gamma) & <P_{F}^{*}(0)=\xi \pi_{F}^{m}\left(K^{*}(0)\right)+(1-\xi) \pi_{F}^{s}\left(K^{*}(0)\right)-I\left(K^{*}(0)\right) \\
& <\xi \pi_{F}^{m}\left(K^{*}(0)\right)+(1-\xi) \pi_{F}^{m}\left(\delta K^{*}(0)\right)-I\left(K^{*}(0)\right) \\
& =P_{F}^{n c}\left(K^{*}(0)\right. \\
& <P_{F}^{n c}\left(K^{n c *}\right) \\
& =P_{F}^{n c *}
\end{aligned}
$$

for all $\gamma \in[0, \bar{\gamma}]$. Furthermore, we have that

$$
\begin{aligned}
P_{F}^{*}(\gamma) & =\pi_{F}^{s}\left(\bar{K}_{s}\right)-I\left(\bar{K}_{s}\right) \\
& \left.<\xi \pi_{F}^{m}\left(\bar{K}_{s}\right)+(1-\xi) \pi_{F}^{m}\left(\delta \bar{K}_{s}\right)\right)-I\left(\bar{K}_{s}\right) \\
& =P_{F}^{n c}\left(\bar{K}_{s}\right) \\
& <P_{F}^{n c}\left(K^{n c *}\right) \\
& =P_{F}^{n c *},
\end{aligned}
$$

for all $\gamma \in(\bar{\gamma}, 1]$. Hence, we obtain that $P_{F}^{n c *}>P_{F}^{*}$ for all $\gamma \in[0,1]$.

\section{Proof of Proposition 6}

(i) The claim follows directly from the discussion in the main text.

(ii) To check that $\tilde{K}_{s}(\gamma)$ is decreasing in $\gamma$ we just have to verify that

$$
\frac{\partial^{2} \tilde{P}_{F}^{s}(K, \gamma)}{\partial K \partial \gamma}=-\xi \Delta \pi_{E}^{\prime}(K)
$$

is negative, which follows from Assumption 2.

In order to show that $\tilde{K}_{s}(\gamma)>K^{*}(\gamma)$ for all $\gamma \in(0,1)$, we note first that

$$
\tilde{P}_{F}^{s}(K ; \gamma)-P_{F}^{s}(K)=\xi(1-\gamma) \Delta \pi_{E}(K) .
$$

By Assumption 2, we have

$$
\frac{\partial\left(\tilde{P}_{F}^{s}(K ; \gamma)-P_{F}^{s}(K)\right)}{\partial K}=\xi(1-\gamma) \Delta \pi_{E}^{\prime}(K)>0 .
$$

This implies that $\tilde{K}_{s}(\gamma)>\bar{K}_{s}$. Furthermore,

$$
\tilde{P}_{F}^{s}(K ; \gamma)-P_{F}^{m}(K ; \gamma)=\xi\left(\Delta \pi_{E}(K)-\Delta \pi_{F}(K)\right)
$$

that, again by Assumption 2, implies $\tilde{K}_{s}(\gamma)>\bar{K}_{m}(\gamma)$. Hence, we have that $\tilde{K}_{s}(\gamma)>$ $K^{*}(\gamma)$ for all $\gamma \in(0,1)$.

Finally, by taking into account the definition of $\tilde{K}_{s}$ and $K^{e f f}$, and noting that direct 
calculation shows that

$$
\begin{aligned}
\frac{\partial\left(\tilde{P}_{F}^{s}(K ; \gamma)-\left(\pi_{F}^{s}(K)+\pi_{E}^{s}(K)-I(K)\right)\right)}{\partial K} & =\xi(1-\gamma) \Delta \pi_{E}^{\prime}(K)-\pi_{E}^{s}{ }^{\prime} \\
& <(\xi(1-\gamma)-1) \Delta \pi_{E}^{\prime}(K) \\
& <0,
\end{aligned}
$$

it follows that $\tilde{K}_{s}(\gamma)<K^{e f f}$. 